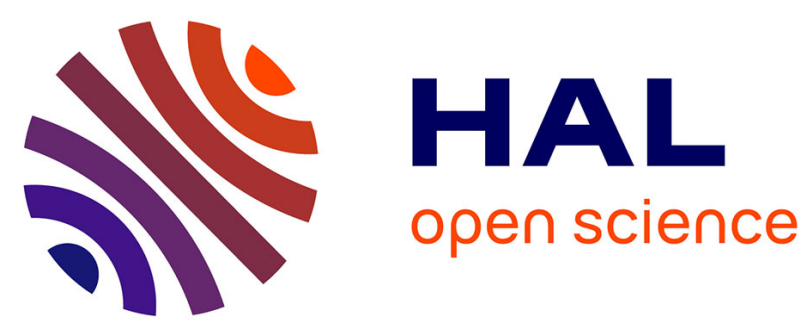

\title{
Synthesis of axially chiral biaryl thioglycosides through thiosugar-directed Pd-catalyzed asymmetric $\mathrm{C}-\mathrm{H}$ activation
}

Maha Fatthalla, Nicolas Grimblat, Etienne Brachet, Mouad Alami, Vincent Gandon, Franck Le Bideau, Samir Messaoudi

\section{To cite this version:}

Maha Fatthalla, Nicolas Grimblat, Etienne Brachet, Mouad Alami, Vincent Gandon, et al.. Synthesis of axially chiral biaryl thioglycosides through thiosugar-directed Pd-catalyzed asymmetric $\mathrm{C}-\mathrm{H}$ activation. Chemical Communications, 2021, 57 (80), pp.10355-10358. 10.1039/d1cc03971g . hal03425421

\section{HAL Id: hal-03425421 \\ https://hal.science/hal-03425421}

Submitted on 10 Nov 2021

HAL is a multi-disciplinary open access archive for the deposit and dissemination of scientific research documents, whether they are published or not. The documents may come from teaching and research institutions in France or abroad, or from public or private research centers.
L'archive ouverte pluridisciplinaire HAL, est destinée au dépôt et à la diffusion de documents scientifiques de niveau recherche, publiés ou non, émanant des établissements d'enseignement et de recherche français ou étrangers, des laboratoires publics ou privés. 
Received 00th January 20xx, Accepted 00th January 20xx

DOI: $10.1039 / x 0 x x 00000 x$

\title{
Synthesis of Axially Chiral Biaryl Thioglycosides through Thiosugar-Directed Pd-Catalyzed Asymmetric C-H Activation
}

\author{
Maha Fatthalla, ${ }^{a, b}$ Nicolas Grimblat, ${ }^{c, d}$ Etienne Brachet, ${ }^{e}$ Mouad Alami, ${ }^{b}$ Vincent Gandon, ${ }^{c, f}$ Franck
} Le Bideau ${ }^{b}$ and Samir Messaoudi ${ }^{b}$ *

Herein we report for the first time that the thiosugar moiety can be used both as a directing group enabling the regioselective activation of a C-H bond of biaryl scaffolds and as a chiral source inducing axial chirality. Our approach enables the easy generation of complex thioglycoside atropoisomers, thus paving the way to new products of potential biological interest.

While biaryl scaffolds are of great prevalence in natural and medicinal compounds, ${ }^{1}$ such motifs incorporating a sugar moiety are still scarce. As naturally occurring substances, a few sugar-functionalized biaryl molecules (Chart 1) have been isolated from Calophyllum membranaceum, ${ }^{2}$ Pyracantha fortuneana $(\mathbf{1})^{3}$ Stellaria dichotoma $(\mathbf{2})^{4}$ and Lysimachia clethroides ${ }^{5}$ whose stems, bark fruits and roots have been used in traditional Chinese medicine. Compounds $\mathbf{3 a , b}$ were found in Streblus asper ${ }^{6}$ and Magnolia officinalis, ${ }^{7}$ while their synthetic homologue $3 c$ was shown ${ }^{8}$ to be a promising molecule for the development of a new class of antidepressant drugs. Ellagitannins are natural polyphenols which belong to a hydrolysable class of tannins and possess one or more hexahydroxybiaryl units around a central glucose core. ${ }^{9}$ Among them, corilagin 4, isolated in 1951 from Caesalpinia coriaria, demonstrated a stronger antitumor activity. ${ }^{10}$ In $1995,{ }^{11}$ a series of ( $\alpha$-D-mannopyranosyl)biphenyl substrates $\mathbf{5}$ were assayed for their ability to inhibit the binding of E-, P-, and Lselectin- IgG fusion proteins to sLex expressed on the surface of HL60 cells. Such diversity in the biological activity of sugarfunctionalized biaryl molecules makes their thio- analogues prime candidates for the design of new bioactive biphenyl glycosides. Indeed, thiosugars can be used as glycomimetic being much more stable to both chemical and enzymatic degradation. In this context, we reported recently two approaches towards a wide range of biaryl thioglycosides 6 via

${ }^{a}$ Department of Chemistry, Faculty of Science, Helwan University, 11795 Ain Helwan, Cairo, Egypt

b. Université Paris-Saclay, CNRS, BioCIS, 92290, Châtenay-Malabry, France. E-mail: samir.messaoudi@u-psud.fr

c. Laboratoire de Chimie Moléculaire (LCM), CNRS UMR 9168, Ecole Polytechnique, Institut Polytechnique de Paris, route de Saclay, 91128 Palaiseau Cedex, France

d. Instituto de Química Rosario (IQUIR, CONICET-UNR) and Facultad de Ciencias Bioquímicas y Farmacéuticas, Universidad Nacional de Rosario, Suipacha 531 S2002LRK, Rosario, República Argentina

e. Université de Paris, Faculté de Pharmacie de Paris, UMR CNRS 8038 (CiTCoM), 4 avenue de l'Observatoire, Paris FR-75006, France

f. Université Paris-Saclay, CNRS, ICMMO, 91405, Orsay Cedex, France

Electronic Supplementary Information (ESI) available: Experimental procedures, characterization data of all new compounds and NMR spectra. See DOI: $10.1039 / x 0 x x 00000 x$ (i) the activation of a $\mathrm{Pd}-\mathrm{G}_{3}$-catalyst with various glycosyl thiols $^{12}$ and (ii) the one pot multicomponent coupling of dihalogenated arenes with thiosugars and boronic acids. ${ }^{13}$ Based on our previous results and our ongoing interest in metal-catalyzed functionalization

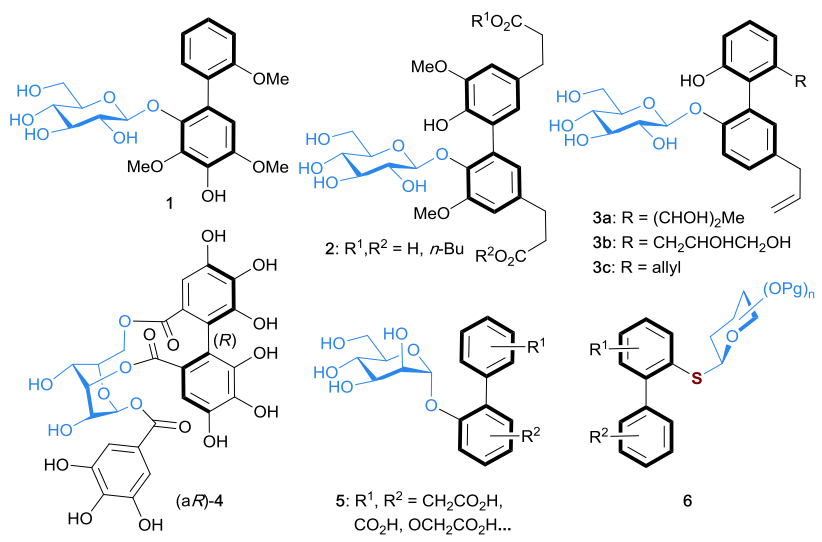

Chart 1 Examples of natural and synthetic biaryl ortho O- and S-glycosides.

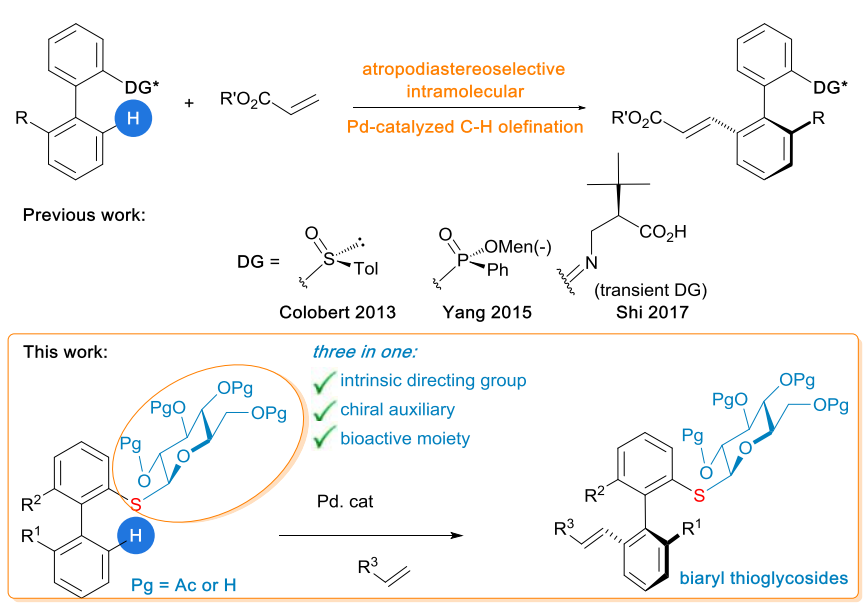

Scheme 1 synthesis of chiral biaryl scaffolds controlled by an internal directing group

of thiosugar motifs, ${ }^{14}$ we were interested to develop an efficient catalytic method to perform easy post functionalization of the biaryl thioglycosides (Scheme 1). Our strategy relies on the use of the thiosugar moiety as $(i)$ an intrinsic directing group for controlling the $\mathrm{C}-\mathrm{H}$ metalation and selective functionalization ${ }^{15}$ and (ii) as a function that will bring original properties to the glycoside for discovering new biological activities. One of the main challenges of this 
approach is the ability of the homochiral thiosugar motif in promoting the axial chirality during the $\mathrm{C}-\mathrm{H}$ activation process. ${ }^{16}$ Such a strategy was reported previously by using sulfoxides, $^{17}$ (-)-menthyl phenylphosphate ${ }^{18}$ and transient imines ${ }^{19}$ as chiral auxiliary in an atropodiastereoselective Pdcatalyzed $\mathrm{C}-\mathrm{H}^{20}$ olefination of biaryls with acrylates (Scheme 1). If successful, our strategy would provide not only straightforward way to post-functionalize biphenyl thioglycosides but also an efficient approach to generate complex glycoside atropoisomers thus paving the way to new products of potential biological interest.

To test the feasibility of our hypothesis, we chose the methyl substituted biphenyl tetra-O-acytelated 1- $\beta$-Dthioglucopyranose $7 a$ as a model study. This later was prepared by coupling of 1-iodo-2-bromobenzene, tetra- $O$ acytelated 1 - $\beta$-thioglucose and 2-methyl phenylboronic acid under Pd-catalysis according to our previously reported protocol (see the ESI). Under these conditions, 7a was prepared as a mixture of two atropoisomers in a 1:1 ratio determined by ${ }^{1} \mathrm{H}$ NMR.

We started our optimization study (Table 1, further details can be found in Tables S1-S4, ESI) by carrying out the reaction of rac-7a with methyl acrylate ( 2 equiv) in the presence of a catalytic amount of $\mathrm{Pd}(\mathrm{OAc})_{2}(10 \mathrm{~mol} \%)$ and excess $\mathrm{AgOAc}(6$ equiv) in a mixture of DCE/HFIP solvents (DCE: 1,2dichloroethane, HFIP: $1,1,1,3,3,3$-hexafluoropropanol) at $80{ }^{\circ} \mathrm{C}$ under argon. Pleasingly, the desired compound 8a was obtained as diastereomeric mixture $(d r=1.3: 1)$, albeit in only $10 \%$ yield (entry 1 , Table 1 ). Interestingly, the yield of 8 a was increased significantly to $35 \%$ yield $(d r=1.1: 1)$ when the reaction was performed under atmospheric air for $4 \mathrm{~h}$. These preliminary results indicate clearly that the thiosugar scaffold is not only acting as a directing group for $\mathrm{C}-\mathrm{H}$ activation in position 2' of the biaryl core but also induces atropodiastereoselectivity during the $\mathrm{C}-\mathrm{H}$ functionalization process. This outcome inspired us to explore this alkenylation reaction under air. Doubling the amount of $\operatorname{Pd}(\mathrm{OAc})_{2} \quad(20 \mathrm{~mol} \%$, entry 2 vs 3 ) led to the desired compound $8 \mathbf{a}$ in $76 \%$ yield and a diastereomeric ratio of $1.6: 1$. Increasing the temperature to $120{ }^{\circ} \mathrm{C}$ (entry 7 vs 8 , Table S1), the acrylate proportion to 6 equiv (entry 7 vs 8 , Table S1) or replacing the atmospheric air with oxygen (entry 6 vs 8 , Table S1) had no particular influence on the course of the reaction. The crucial role of HFIP on the yield and stereochemical course of the reaction reported ${ }^{17 \mathrm{~b}, 21}$ when using a sulfoxide moiety as a directing group was not observed in our case. On the contrary, the reaction performed in DCE led to a better diastereomeric ratio (2:1) than in HFIP $(d r=0.9: 1)$, in lower yields in both cases (entry 4 vs 5). Importantly, conducting the same reaction with only 2 equiv of $\mathrm{AgOAc}$ as an oxidant furnished the desired product $8 \mathbf{a}$ in the same yield (76\%) and a $d r$ of 1.4:1 (entry 3 vs 7, Table 1). However, performing the coupling in the absence of AgOAc produced $8 \mathrm{a}$ in a poor $16 \%$ yield (entry 6 Table 1 ). To determine the atropostability of $\mathbf{8 a}$, variable temperature $1 \mathrm{H}$ NMR studies were performed in the aim to measure the coalescence temperature and calculate the energy barrier. However, the total coalescence was not reached even when performing the $1 \mathrm{H} \mathrm{NMR}$ at $373 \mathrm{~K}$ (for more details on the atropostabilty studies, see SI, P47-48). This result indicates clearly that the biarylthioglycoside $\mathbf{8 a}$ is configurationally stable at the reaction temperature.

Table 1: optimization of the reaction conditions.

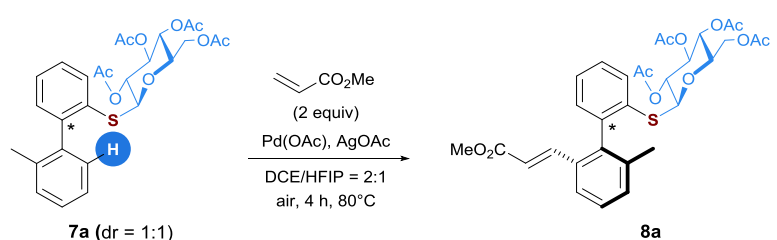

$7 \mathbf{a}(\mathrm{dr}=1: 1)$

\begin{tabular}{llllll} 
entry & solvent & AgOAc (equiv) & $\begin{array}{l}\mathrm{Pd}(\mathrm{OAc})_{2} \\
(\%)\end{array}$ & Yield $^{\mathrm{b}}(\%)$ & $\mathrm{dr}^{\mathrm{c}}$ \\
\hline $\mathbf{1}^{\mathrm{d}}$ & DCE/HFIP & 6 & 10 & 10 & $1.3: 1$ \\
2 & DCE/HFIP & 6 & 10 & 35 & $1.1: 1$ \\
3 & DCE/HFIP & 6 & 20 & 76 & $1.6: 1$ \\
4 & HFIP & 6 & 20 & 66 & $0.9: 1$ \\
5 & DCE & 6 & 20 & 50 & $2.1: 1$ \\
6 & DCE/HFIP & - & 20 & 16 & $1.2: 1$ \\
$\mathbf{7}$ & DCE/HFIP & $\mathbf{2}$ & $\mathbf{2 0}$ & $\mathbf{7 6}$ & $\mathbf{1 . 4 : 1}$ \\
\hline
\end{tabular}

${ }^{a}$ Reaction conditions: substituted thioglycoside $7 \mathrm{a}(0.15 \mathrm{mmol})$, solvent $(0.1 \mathrm{M})$, ${ }^{\mathrm{b}}$ Yield refers to the isolated product after column chromatography, ${ }^{\mathrm{c}}$ diastereomeric ratio (d.r.) were determined using HPLC-Ms and expressed as a ratio from polar isomer to less polar isomer, ${ }^{\mathrm{d}} 17$ hours under argon.

With the optimized conditions in hand (entry 7, Table 1), we next investigated the scope and limitations of this $\mathrm{C}-\mathrm{H}$ alkenylation process by systematically varying the nature of the alkene and the biaryl thioglycosides 7 . The substrate scope for alkenes was first explored keeping biphenyl $7 a$ as the substrate (Scheme 2). Ethyl acrylate showed identical reactivity to the methyl one and furnished $\mathbf{8 b}$ in $76 \%$ yield and a $d r=1.4: 1$. However, the diastereomeric ratio was increased to $10: 1$ when $t$-butyl acrylate was used (compound $8 \mathrm{c}$ ). In addition, the reaction proved compatible with a wide array of substituted alkenes such as acrylamide (8d, $d r=2: 1), N, N$ dimethyl acrylamide $(\mathbf{8 f}, \mathrm{dr}=1.5: 1)$, vinyl ketones $(8 \mathrm{e}, \mathrm{dr}=2: 1)$, vinyl phosphonates $(\mathbf{8 i}, \mathrm{dr}=2.6: 1)$ and vinyl nitriles $(\mathbf{8 g}, \mathrm{dr}=$ 1.8:1). Of note, in the case of this later (compound $\mathbf{8 g}$ ) a mixture of $E$-and $Z$-isomers were formed in addition to the two atropoisomers (see ${ }^{1} \mathrm{H}$ NMR of $\mathrm{SI}$ ). In addition, this $\mathrm{C}-\mathrm{H}$ alkenylation tolerates 1,2-disubstitued alkenes such as transmethyl crotonate, which produced product $\mathbf{8 h}$ in a diastereomeric ratio of $2: 1$. Interestingly, reaction of $7 a$ with 1,1 ethyl methylacrylate gave the non-conjugated product $8 \mathbf{j}$ in $47 \%$ yield due to the easiness of the syn 6 -hydride elimination from hydrogen away from the aromatic ring.

Olefination starting from the less reactive styrene substrates was also examined under our optimized conditions. Although the conversion rates are not total in all cases $(<50 \%)$ and the desired products were obtained in low to moderate yields (1544\%) (Scheme 2), the diastereoselectivity observed for compounds $\mathbf{8 k}-\mathbf{m}$ are excellent $(d r>20: 1)$. The presence of electron-withdrawing groups in the para-position of the styryl ring plays a positive role on the $\mathrm{C}-\mathrm{H}$ olefination process, giving higher yields than electron-rich ones ( 38 and $44 \%$ for 81 and 8 n vs 15 and $22 \%$ for $\mathbf{8 k}$ and $\mathbf{8 m}$ ). Surprisingly, the diastereomeric ratio of compound $8 \mathbf{n}$ is low $1: 1$ compared to the other styryl congeners $\mathbf{8 I}, \mathbf{8 m}$ and $\mathbf{8 k}(d r>20: 1)$. 


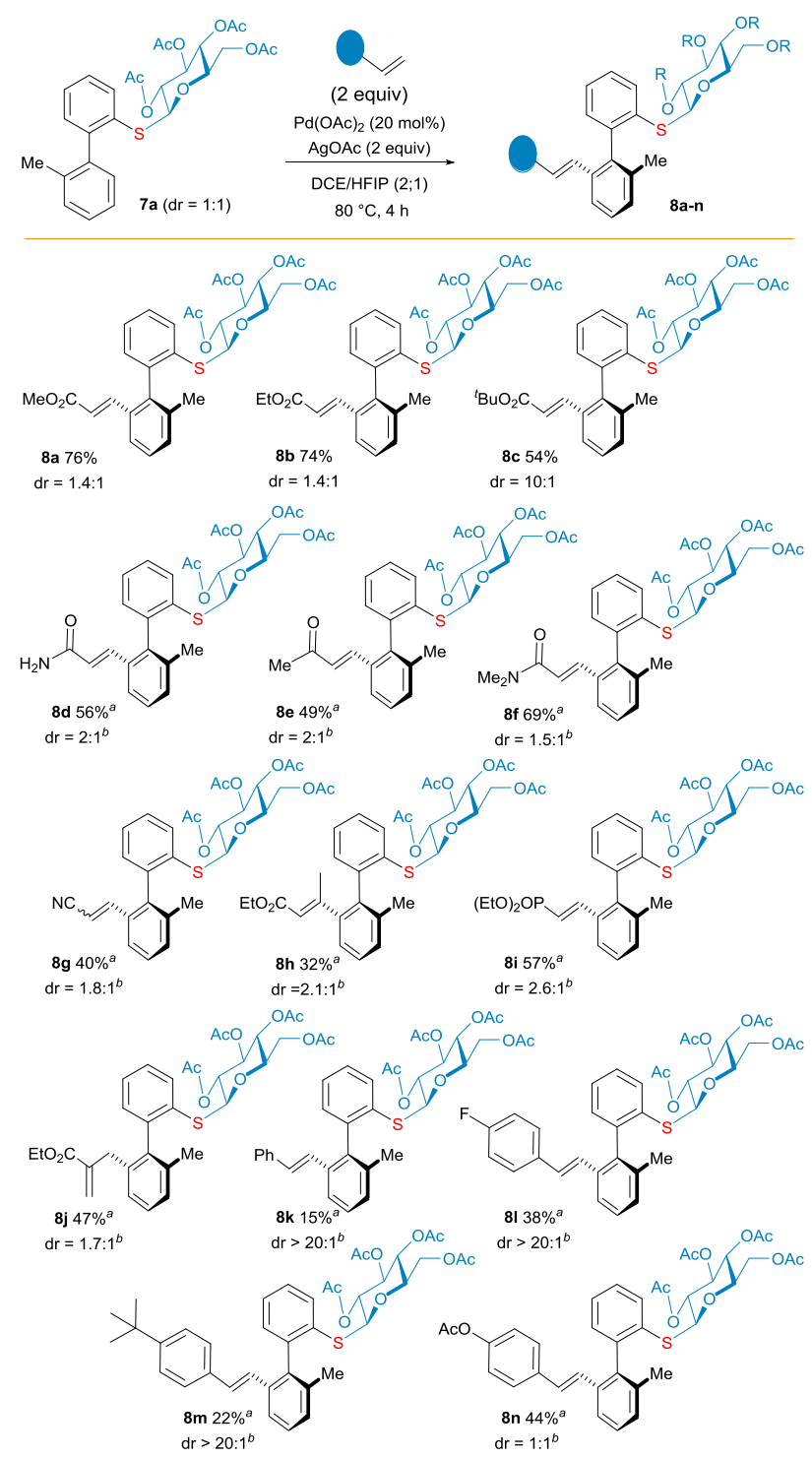

Scheme 1 scope of the reaction varying the olefin partner. ${ }^{a}$ isolated yield ${ }^{b}$ diastereomeric ratio $(d r)$ was determined by ${ }^{1} \mathrm{H}$ NMR and/or by HPLC-MS.

Next, we investigated the reactivity of a series of biaryl thioglucosides $\mathbf{7 b}$-e (Scheme 3 ) synthesized under the modified

conditions (see ESI) as mixtures of both diastereoisomers (entry 7 , Table 1 ). In general, moderate yields (30\% to 60\%) and same diatereomeric ratios (from $1.3: 1$ to $1.5: 1$ ) were obtained when the methyl is replaced by a fluorine atom (9b) or a methoxy group (9c). It can be noted that in the case of compound 7c, $26 \%$ of dicoupling adduct 10 were isolated beside 9c (see ESI). In addition, naphthalene 9e was synthesized in $60 \%$ and a $d r$ of $2: 1$. Importantly, the best diastereomeric ratio was observed with methyl acrylate when the tri ortho-substituted biaryl substrate 7d was used. Under the optimized conditions, $E$-alkenyl biphenyl $9 \mathbf{d}$ was isolated in an excellent $d r>20: 1$.

Finally, we were intrigued whether the coupling may be conducted with biphenyl $\mathbf{1 1}$ bearing an unprotected sugar unit
(Scheme 4). Thus, performing the reaction with methyl acrylate

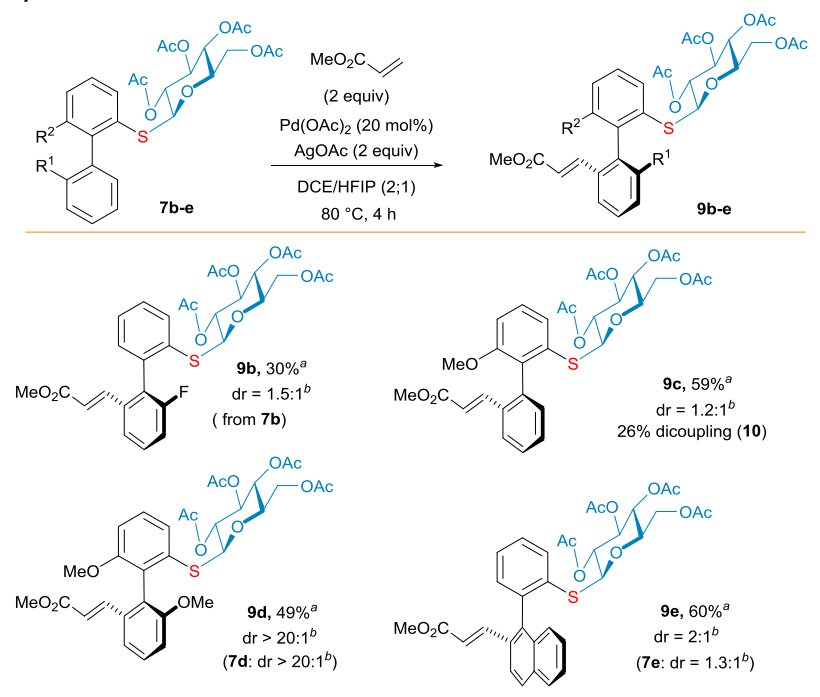

Scheme 3 scope of the reaction varying the biaryl thioglycoside partner 7 . $^{a}$ isolated yield. ${ }^{b}$ diastereomeric ratio (dr) was determined by ${ }^{1} \mathrm{H}$ NMR and/or by HPLC-Ms

under our best conditions at $80^{\circ} \mathrm{C}$ led only to degradation products but surprisingly, biaryl thioglycoside $\mathbf{1 2}$ (Scheme 4) was synthesized in $22 \%$ yield and a good diastereomeric ratio $(d r=4.3: 1)$ when the $\mathrm{C}-\mathrm{H}$ olefination reaction was conducted at room temperature in HFIP. This preliminary result suggests that unprotected thiosugar, which induced a higher diastereoselectivity than its acetylated congener, could constitute an excellent approach to synthesize atroposelectively biaryl thioglycosides.

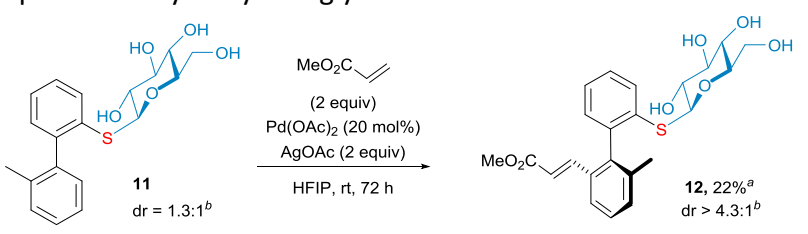

Scheme 4 Using unprotected thiosugar as a chiral directing group. ${ }^{a}$ isolated yield. ${ }^{b}$ diastereomeric ratio $(d r)$ was determined by ${ }^{1} \mathrm{H}$ NMR.

To get insight into the reaction mechanism and the observed atroposelectivity induced by the sugar moiety, Density Functional Theory (DFT) calculations were performed (see ESI for details). One of the main goals of this theoretical study was to understand the reason why one isomer is favored and which could be the major atropoisomer. With an analogous approach as the one we previously reported, ${ }^{22}$ we focused on the key step of the reaction, the concerted metalation deprotonation (CMD) for the analogous protected (7a) and unprotected (11) compounds.

In the case of the unprotected thiosugar, in agreement with the high experimental $d r$ (>4.3:1), a clear selectivity is observed towards the $a R$ isomer. A difference barrier of almost $3 \mathrm{kcal} / \mathrm{mol}$ in favour of this isomer was computed, the $a R$ product being $3.85 \mathrm{kcal} / \mathrm{mol}$ more stable than its as counterpart (Figure 1). Both account for a 100:0 selectivity. Looking now at the protected thiosugar, as observed in Scheme 2, the $d r$ of $7 a$ with different reagents vary from 1.4:1 to $>20: 1$. Interestingly, the results of the calculations show 
that the ratios obtained with the protected sugar model, is regulated by both the energy barrier as well as the thermodynamics of the reaction. The comparison of the energy barriers gives an aS:aR 85:15 selectivity, while the exergonic thermodynamic analysis reverses the selectivity to $a S: a R$ 0:100. This suggests that the interplay between the kinetics and the thermodynamics of the reaction is actually responsible of the selectivity of the reaction.

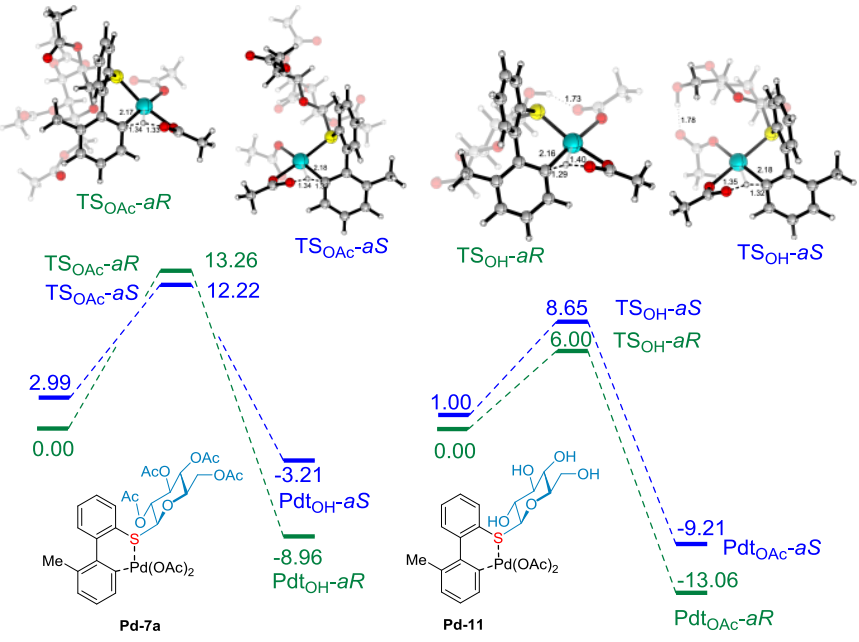

Figure $11 \omega B$ 97XD/SDD $(P d)-6-311+G(d, p) / / B 3 L Y P / L A N L 2 D Z(P d)-6-31+G(d, p)$ free energy profiles with SMD solvent correction (relative $\Delta G_{353.15}$ for 7 a and $\Delta G_{273.15}$ for $\mathbf{1 1}$ in $\mathrm{kcal} / \mathrm{mol}$ ) of the CMD step for the protected (7a) and unprotected (11) thiosugars. Selected distances (in $\AA$ ) are shown in the transition structures.

In summary, we described here for the first time that thiosugar unit attached to biaryl core is able to both act as a directing group for alkenylation in position $2^{\prime}$ and induce atropodiastereoselectivity during the $\mathrm{C}-\mathrm{H}$ functionalization process. This method provides an unprecedented access to alkenylated biaryl thioglycosides with high diastereoselectivity in some cases. A variety of olefin partners including acrylates, acrylamides, vinyl ketones, nitriles, phosphonates, and styrenes were tolerated in this reaction. Furthermore, computational mechanistic investigations has provided evidence that directing group effect and atroposelectivity are derived by the spatial positioning of the sugar.

Authors acknowledge support of this project by CNRS, University Paris-Saclay, Ecole Polytechnique and Helwan University.

There are no conflicts to declare.

\section{Notes and references}

1. S. Yuan, J. Chang and B. Yu Topics Curr., Chem. 2020, 378, 23.

2. J. Zou, D. Jin, W. Chen, J. Wang, Q. Liu, X. Zhu and W. Zhao, J. Nat. Prod., 2005, 68, 1514.

3. Y. Dai, G.-X. Zhou, H. Kurihara, W.-C. Ye and X.-S. Yao, J. Nat. Prod., 2006, 69, 1022.

4. T. Morikawa, B. Sun, H. Matsuda, L. J. Wu, S. Harima and M. Yoshikawa, Chem. Pharm. Bull., 2004, 52, 1194.

5. D. Liang, H. Luo, Y.-F. Liu, Z.-Y. Hao, Y. Wang, C.-L. Zhang, Q.-J. Zhang, R.-Y. Chen and D.-Q. Yu, Tetrahedron, 2013, 69, 2093.
6. C. Li, C. Huang, T. Lu, L. Wu, S. Deng, R. Yang and J. Li, Rapid Commun. Mass Spectrom., 2014, 28, 2363.

7. R.-Y. Yan, H.-L. Liu, J.-Y. Zhang and B. Yang, J. Asian Nat. Prod. Res., 2014, 16, 400.

8. T.-H. Yang, Y.-B. Ma, C.-A. Geng, D.-X. Yan, X.-Y. Huang, T.-Z. Li, X.-M. Zhang and J.-J. Chen, Eur. J. Med. Chem., 2018, 156, 381.

9. H. Yamada, S. Wakamori, T. Hirokane, K. Ikeuchi and S. Matsumoto, Molecules, 2018, 23, 1901.

10. J. Liu, X. Qin, W. Ma, S. Jia, X. Zhang, X. Yang, D. Pan and F. Jin, Mol. Med. Rep., 2021, 23, 320.

11. T. P. Kogan, B. Dupré, K. M. Keller, I. L. Scott, H. Bui, R. V. Market, P. J. Beck, J. A. Voytus, B. M. Revelle and D. Scott, J. Med. Chem., 1995, 38, 4976.

12. R. A. A. AL-Shuaeeb, C. Dejean, M. Alami and S. Messaoudi, Chem. Asian J., 2017, 12, 3114.

13. S. Benmahdjoub, N. Ibrahim, B. Benmerad, M. Alami and S. Messaoudi, Org. Lett., 2018, 20, 4067.

14. Selected articles: a) E. Brachet, J. -D. Brion, S. Messaoudi, M. Alami, Adv. Synth. Catal. 2013, 355, 2627; b) E. Brachet, J. -B. Brion, S. Messaoudi, M. Alami, Adv. Synth. Catal. 2013, 355, 477; c) A. Bruneau, M. Roche, A. Hamze, J. -D. Brion, M. Alami, S. Messaoudi, Chem. Eur. J. 2015, 21, 8375; d) R. A. A. AL-Shuaeeb, D. Montoir, M. Alami, S. Messaoudi, J. Org. Chem. 2017, 82, 6720; e) N. Probst, R. Lartia, O. Théry, M. Alami, E. Defrancq, S. Messaoudi, Chem. Eur. J. 2018, 24, 1795; f) D. Montoir, M. Amoura, Z. E. -A. Ababsa, T. M. Vishwanath, E. Yen-Pon, V. Robert, M. Beltramo, V. Piller, M. Alami, A. Aucagne, S. Messaoudi, Chem. Sci., 2018, 9, 8753 ; g) M. Zhu, G. Dagousset, M. Alami, S. Magnier, S. Messaoudi, Org. Lett. 2019, 21, 5132 ; h) M. Zhu, M. Alami, S. Messaoudi, S. Chem. Chomm. 2020, 56,4464

15. For references on the use of S-based DGs, see: a) K. Tang, C. Wang, T. Gao, L. Chen, L. Fan,L Sun, Adv. Synth. Catal. 2019, 361, 26. b) M. Yu, Y. Xie, C. Xie, Y. Zhang, Org. Lett., 2012, 14, 2164. c) X. Zhang, Y. Zhang, K. Chen, Z. Shi, Org. Chem. Front., 2014, 1, 1096. d) X. S. Zhang, Q. L. Zhu, Y.F. Zhang, Y.B. Li, Z. J. Shi, Chem. Eur. J. 2013, 19, 11898

16. For review in asymmetric synthesis of biaryl, see (a) H.-M.; Chen, G. Liao, C.-K. Xu, Q.-J. Yao, S. Zhang, B.-F. Shi, CCS Chem. 2021, 3, 455; (b) Maria I. Lapuh, Sara Mazeh, and Tatiana Besset ACS Catal. 2020, 10, 12898. (c) J. Wencel-Delord, A. Panossian, F. R. Leroux and F. Colobert, Chem. Soc. Rev., 2015, 44, 3418; (d) J. Wencel-Delord and F. Colobert, Synlett, 2015, 26, 2644; (e) G. Liao, T. Zhou, Q.-J. Yao, B.-F. Shi, Chem. Commun., 2019, 55, 8514.

17. (a) T. Wesch, F. R. Leroux and F. Colobert, Adv. Synth. Catal., 2013, 355, 2139, (b) Q. Dherbassy, G. Schwertz, M. Chessé, C. K. Hazra, J. Wencel-Delord, F. Colobert, Chem. - Eur. J. 2016, 22, 1735; (c) Q. Dherbassy, J.-P. Djukic, J. Wencel-Delord, F. Colobert, Angew. Chem. Int. Ed. 2018, 57, 4668.

18. Y.-N. Ma, H.-Y. Zhang and S.-D. Yang, Org. Lett., 2015, 17, 2034.

19. Yao and B.-F. Shi, Chem. Commun., 2019, 55, 8514.

20. For a recent review in asymmetric $\mathrm{C}-\mathrm{H}$ activation using a transient directing group, see: G. Liao, T. Zhang, Z.-K. Lin, B.-F. Shi Angew. Chem. Int. Ed. 2020, 59, 19773;

21. For a recent review on the magic role of HFIP in C-H activation process, see: T. Bhattacharya, A. Ghosh, D. Maiti, Chem. Sci., 2021, 12, 3857-3870

22. J. Ghouilem, C. Tran, N. Grimblat, P. Retailleau, M. Alami, V. Gandon, S. Messaoudi, ACS Catal. 2021, 11, 1818. 